\title{
Assessment of test methods for the durability of thermal mortars
}

\section{exposure to freezing}

\author{
J. Maia ${ }^{(1)}$, Nuno M. M. Ramos ${ }^{(1)}$, R. Veiga ${ }^{(2)}$
}

(1) CONSTRUCT-LFC, Faculty of Engineering (FEUP), University of Porto, Porto, Portugal, Rua Dr. Roberto Frias s/n, 4200-465 Porto, Portugal.

(2) LNEC, National Laboratory for Civil Engineering, Lisbon, Portugal, Av. do Brasil 101, 1700-066 Lisbon, Portugal.

*Corresponding author:

E-mail: joanamaia@fe.up.pt, Tel: 00351225083732

\begin{abstract}
Thermal mortars are a trend in the construction industry in recent years, owing to the required decrease of the thermal transmission of building envelopes. The high porosity of thermal mortars leads to permeability values that can affect their durability since it creates more favourable conditions for the penetration of aggressive agents. Water is observed as one of the most common and harmful degradation agents. Regarding the climatic variability in Europe, freezing is a usual degradation mechanism both in severe and moderate climates. Since thermal mortars have higher water absorption than a common insulation, the freezing may occur. As no durability assessment methodologies to evaluate the exposure of thermal mortars to freezing degradation mechanisms exist, the present work has the objective to analyse existing accelerated ageing procedures, which envisage freezing degradation mechanism. As such, the durability assessment described in EN 1015-21 and ETAG 004 was adapted and implemented in different thermal mortars. It was observed that the higher number of cycles and the severity of the freeze-thaw ageing cycles, according to ETAG 004, may reproduce the effect of the northern European climates, while the ageing cycles, described in EN 1015-21, combine
\end{abstract}


degradation mechanisms that occur in central and southern European climates. This adaptation allowed collecting reliable data and inputs to the development of durability assessment methodologies directly applicable to thermal rendering and plastering systems.

KEYWORDS: Thermal mortar, Durability, Accelerated ageing, Experimental tests,

\section{Degradation mechanisms.}

\section{INTRODUCTION}

The development of materials with an enhanced service life contributes to lower production and accumulation of waste and, consequently, to obtain sustainable building solutions [1]. Thus, in order to protect the built environment, it is necessary to study, analyse and act in order to control and increase the durability of the materials, components and constructions.

The pore structure has a high impact on the hygrothermal performance of mortars since permeability depends on the porous network, its connection, size, shape and distribution of the pores [2]. Open porosity reflects the interconnected pores, which allow water transport, and the pore size distribution, influencing the amount that is transported. The higher the amount of evaporated water during the production of a mortar, the higher the resulting porosity in the hardened material, and thus the lower the mechanical strength and the potential durability of this material, compared to a material with lower porosity [3]. In general, the way degradation agents penetrate the material depends on the transport mechanisms through the porous network, namely, the permeability and capillary water absorption [4]. The pore structure, particularly the capillary network, has a very high impact on the durability of mortars. Since the capillary network is continuous, it has a major effect on the transport process, while the macropores are often isolated. However, the difference between the porosity of a material and its permeability should be noted. Increasing the porosity of a material tends to increase the permeability, which 
affects its durability since it creates more favourable conditions for the penetration of aggressive agents inside the material [5].

The analysis of the existing standardisation for the durability assessment of hardened mortars does not allow a consistent evaluation considering innovative mortars in general. Concerning thermal mortars, the experience documented in the literature is limited, despite the several industrial solutions available in the European market [6]. Accelerated ageing tests carried out by several authors do not follow a methodology directly related to actual performance. Hence, they may not be the most appropriate way of evaluating the material/system. Regardless of the matrix and aggregates used in the mortar, accelerated ageing cycles are performed. A trend regarding temperatures is observed, being the temperature in the freezing period approximately $-20^{\circ} \mathrm{C}$ and in the thawing period carried out at room temperature [7-10]. The lack of requirements in EN 998-1 [11] and the existing test methodology for onecoat mortars, according to EN 1015-21 [12], does not allow to classify and to show the added value of this type of systems, since they are multi-layer systems and should be evaluated as such. Directing the durability evaluation to the desired performance will guarantee more durable solutions, raising the adequacy of this type of systems to the climate where they will be applied. However, this implies the prior definition of the requirements. As such, regarding the climatic variability in Europe, freezing is a common degradation mechanism in both severe (northern Europe) and moderate climates (central/ southern Europe). This paper has the aim to increase the knowledge regarding the durability of thermal mortars applied as a multi-layer system that are being already implemented in the construction industry. As such, since there are no durability assessment methodologies to evaluate the exposure of thermal rendering systems to freezing degradation mechanisms, the present work has the objective to analyse existing accelerated ageing procedures, which envisage freezing degradation mechanism. To 
achieve this main goal, both the durability assessment envisaged in EN 1015-21 and the one described in ETAG 004 will be adapted and implemented in different thermal systems.

\section{BACKGROUND}

\subsection{Degradation mechanisms}

The durability of construction materials is affected by different degradation mechanisms, which usually act together. A deeper knowledge of the main degradation mechanisms and the consequent failure modes will contribute to a more accurate durability evaluation. ISO 156861 [13] presents a summary of the most relevant degradation mechanisms in building materials, taking into account nature and class. The mechanical (expansion and contraction), thermal (heat, frost, thermal shock), chemical (oxygen, acids, lime) and biological (moulds, fungi) agents are the most relevant in the durability of mortars, especially renders. Batchelor et al. [14] grouped several degradation mechanisms considering: (a) Direct mechanical action (wear and fatigue, rupture and deformation); (b) Heating or radiation (thermal degradation and high radiation energy); (c) Presence of chemical agents (corrosion, oxidation, softening, embrittlement, biochemical and biological agents); (d) Combination of two or more of the previously presented mechanisms (such as wear in corrosive or chemically active environments). Focusing on the particular degradation of mortars, some studies present the possible degradation mechanisms and the agents responsible for this degradation. Addleson [15] and Aguiar et al. [16] presented the main causes of degradation on mortars according to the nature of the action and related agents, which are: (a) Water action (humidity, ice and soluble salts); (b) Biological action (algae, fungi and lichens, plants, bacteria and small size animals); (c) Mechanical action (shrinkage, wind, temperature, substrate deformation and accidental actions); (d) Human action (technology, maintenance, tourism, vandalism and pollution). In addition, degradation occurs by the combined action of different mechanisms 
(physical, chemical, mechanical, biological, etc.), which complicates the classification of degradation processes $[17,18]$. The combined action of temperature and water is one of the most common degradation mechanisms in renders, contributing to cracking due to temperature variation and easier water absorption [19]. Water promotes the action of relevant agents, such as freeze-thaw, salts crystallisation and various biological agents. Flores-Colen et al. [20] analysed anomalies in mortars, with or without coating, revealing cracks, slurry, detachments, soiling, differences in tone and biological colonisation, that originate stains, being in most cases associated with the presence of moisture.

Degradation mechanisms act in different ways if different binders are present. A current cement paste is usually constituted by different pore types - capillary, micro and macropores resulting in a complex porous network [21]. Regarding lime-based mortars, they are significantly more permeable compared to hydraulic lime-based and cement mortars, due to higher porosity. As such, the imbibed amount of water is higher and, consequently, the amount of soluble salts is higher as well. In terms of mechanical performance, lime-based mortars present less strength than hydraulic mortars, which promotes a higher risk when subjected to salts crystallisation pressure. On the other hand, knowing that the larger the pores, the lower the crystallisation pressure, the higher pores dimension of lime-based mortars contributes to less mechanical degradation. This fact is due to the formation of crystals inside the pores not producing excessive pressure [22]. However, the degradation of lime-based mortars and masonry materials due to salt crystallisation is an important issue, especially in historical buildings [23-26]. The degradation of lime-based mortars in historical buildings, after rehabilitation, is highly related to the application of coatings with low water vapour permeability, which creates incompatibility between the old and new materials [27]. The different classifications of actions and agents of mortar degradation mechanisms highlight the fact that most of the agents act together. Temperature and water have a great influence on the 
durability of mortars. The identification of the most frequent degradation mechanisms in materials and components helps the development of control measures to avoid failure. In the case of mortars applied as thermal renders, the main degradation mechanisms are presented in Table 1, based on the Guideline on Durability in Buildings [28] and on the Assessment of working life products [29].

Table 1. Summary of the degradation mechanisms, actions, agents, failures and conditions for failure occurrence on mortars.

\begin{tabular}{|c|c|c|c|c|}
\hline $\begin{array}{l}\text { Degradation } \\
\text { mechanisms }\end{array}$ & $\operatorname{Action}(\mathrm{s})$ & Agent(s) & Failure(s) & $\begin{array}{l}\text { Conditions for the } \\
\text { occurrence }\end{array}$ \\
\hline \multirow[b]{2}{*}{ Freeze-thaw } & \multirow[b]{2}{*}{$\begin{array}{l}\text { Thermal/Mechanical/ } \\
\text { Chemical }\end{array}$} & \multirow[b]{2}{*}{$\begin{array}{c}\text { Temperature/Ice/Water/ } \\
\text { Solar radiation }\end{array}$} & Disintegration & \multirow{2}{*}{$\begin{array}{l}\text { High moisture content } \\
\text { during freeze-thaw, } \\
\text { aggravated by chlorides } \\
\text { and lack of drainage }\end{array}$} \\
\hline & & & Appearance & \\
\hline Salts & Chemical & $\begin{array}{l}\text { Lime/Hydroxides } \\
\text { and salts crystallization }\end{array}$ & $\begin{array}{l}\text { Expansion } \\
\text { followed by } \\
\text { disintegration }\end{array}$ & $\begin{array}{l}\text { Silica or dolomite } \\
\text { aggregates in the presence } \\
\text { of moisture; } \\
\text { and soluble salts, like } \\
\text { sulfates and chlorides, in } \\
\text { the presence of moisture }\end{array}$ \\
\hline \multirow[b]{2}{*}{$\begin{array}{l}\text { Leaching of } \\
\text { lime }\end{array}$} & \multirow[b]{2}{*}{ Chemical } & \multirow[b]{2}{*}{ Lime/Hydroxides } & Efflorescence & \multirow{2}{*}{$\begin{array}{l}\text { Vapour transfer and } \\
\text { permeability }\end{array}$} \\
\hline & & & $\begin{array}{c}\text { Mortar } \\
\text { disintegration } \\
\end{array}$ & \\
\hline \multirow{2}{*}{$\begin{array}{l}\text { Biological } \\
\text { attack }\end{array}$} & \multirow{2}{*}{ Biological } & \multirow{2}{*}{ Moulds/Fungi } & Strength & \multirow{2}{*}{$\begin{array}{l}\text { Contact with sewage } \\
\text { (acids generation) }\end{array}$} \\
\hline & & & Disintegration & \\
\hline \multirow[b]{2}{*}{ Shrinkage } & \multirow[b]{2}{*}{ Thermal/Mechanical } & \multirow[b]{2}{*}{$\begin{array}{l}\text { Temperature/Solar } \\
\text { radiation }\end{array}$} & Cracks & \multirow[b]{2}{*}{ High water/cement ratio } \\
\hline & & & $\begin{array}{l}\text { Damages in } \\
\text { adjacent } \\
\text { components }\end{array}$ & \\
\hline $\begin{array}{l}\text { Temperature } \\
\text { fluctuations }\end{array}$ & Thermal/Mechanical & $\begin{array}{l}\text { Temperature/Solar } \\
\text { radiation }\end{array}$ & Cracks & $\begin{array}{l}\text { Large areas and hot } \\
\text { climates }\end{array}$ \\
\hline
\end{tabular}

\subsection{Accelerated ageing procedures}

The identification of relevant standards for the evaluation of the durability of thermal mortars and related systems is an important step to guarantee the development of durable products. Thermal mortars are applied as a multi-layer system, which emphasises the importance in evaluating the system as a whole, due to the specific characteristics and contribution of each layer in the system performance, as demonstrated by Maia et al. [30]. The durability assessment of hardened mortars, envisaged in the EN 998-1 [11], is not an adequate methodology to innovative mortars in multi-layer systems since it is applicable to one-coat 
mortars (referring to the test methodology in EN 1015-21 [12]). ETAG 004 [31] presents specific durability assessment applicable to ETICS (External Thermal Insulation Composite Systems), which are multi-layer thermal systems and present similar characteristics to thermal rendering systems. Despite the referred methodologies are not directly applicable to thermal mortars in multi-layer systems, they may be adopted since similar degradation mechanisms are observed. Nevertheless, there will be a different relative intensity. This fact may contribute with reliable data to the development of applicable durability assessment methodologies.

The EN 1015-21 [12] evaluates the durability of one-coat renders through water permeability, and adhesion tests carried out before and after accelerated ageing tests. The proposed accelerated ageing cycles are heating-freezing and humidification-freezing. Before testing, the samples should be conditioned for 28 days at a temperature of $20 \pm 2{ }^{\circ} \mathrm{C}$ and a relative humidity of $65 \pm 5 \%$. The ageing procedure is composed of two distinct series, of four ageing cycles each, and conditioning of 48 hours at reference conditions (temperature of $20 \pm 2{ }^{\circ} \mathrm{C}$ and a relative humidity of $65 \pm 5 \%$ ) between them. The first series (heating-freezing) is composed of 8 hours of heating using infrared radiation $\left(60 \pm 2^{\circ} \mathrm{C}\right)$, and 15 hours of freezing $\left(-15 \pm 1^{\circ} \mathrm{C}\right)$. The second series (humidification-freezing) consists of immersion of the specimen in water at room temperature for 8 hours and followed by exposure to $-15 \pm 1^{\circ} \mathrm{C}$ during 15 hours. The referred standard does not define any requirements to be met after ageing.

The durability assessment of ETICS, presented in ETAG 004 [31], defines two distinct ageing procedures., They are performed taking into account the obtained water absorption: hygrothermal ageing cycles, combining heat-rain and heat-cold cycles, and freeze-thaw. The hygrothermal ageing cycles are performed in a rig (large-scale sample) while the freeze-thaw is performed in small-scale samples. The heat-rain procedure is composed of 3 hours of heating at $70^{\circ} \mathrm{C}$ and 1 hour of rain $\left(11 / \mathrm{m}^{2} \cdot \min\right.$ of water at $\left.15^{\circ} \mathrm{C}\right)$, repeated 80 times. The heat-cold cycle consists of 8 hours of heating at $50^{\circ} \mathrm{C}$ and 16 hours of freezing at $-20^{\circ} \mathrm{C}$, repeated five times. 
Between the two procedures, drainage for 2 hours and then conditioning for 48 hours at 10$25^{\circ} \mathrm{C}$ are performed. The freeze-thaw procedure consists of 30 cycles of immersing the specimen in water at $23 \pm 2^{\circ} \mathrm{C}$, during 8 hours, and then placing the sample at $-20^{\circ} \mathrm{C}$ for 16 hours. The durability of the tested materials is evaluated through impact resistance, bond strength and capillary water absorption tests after the ageing cycles.

Beyond the referred methodologies, envisaged in existing standards, several researchers evaluated the durability of innovative mortars using non-standardized procedures. Puertas et al. [7] observed that the incorporation of polypropylene fibres increased the resistance to fracture after humidification-heating cycles $\left(50\right.$ cycles of immersion for 18 hours, at $21^{\circ} \mathrm{C}$, and heating for 6 hours, at $70 \pm 5^{\circ} \mathrm{C}$ ). However, cement mortars without fibre addition presented the opposite effect. Gonçalves da Silva [32] evaluated the durability of cement-based mortars with epoxy or polyester resin addition, comparing the two mixtures. Comparing the mechanical strength after ageing ( 12 hours at $20^{\circ} \mathrm{C}$ and 12 hours at $50^{\circ} \mathrm{C}$, for 10000 hours $\approx 417$ cycles), it was observed that the epoxy-based sample presented slightly lower flexural strength than the polyester-based one. Regarding the compressive strength, the sample with the incorporation of epoxy resin presented a significant decrease compared with the polyester resin, also after ageing. FerrándizMas, García-Alcocel [33] studied the durability of a cement-based mortar with EPS addition (by partial replacement of cement). After the implementation of the heat-cold accelerated ageing cycle ( 6 hours at $20^{\circ} \mathrm{C}$ and 18 hours at $60^{\circ} \mathrm{C}$, comprising 25 cycles), a beneficial effect on the compressive strength of the samples with EPS addition was verified. The authors also observed that a higher content of EPS increased durability. Hannawi, Prince-Agbodjan [10] observed that the implementation of heat-cold cycles $\left(12\right.$ hours at $20^{\circ} \mathrm{C}$ and 12 hours at $65^{\circ} \mathrm{C}$, repeated 40 times), promoted an increase of the compressive and flexural strength, which may be due to the formation of new hydrates compounds during the ageing. The previous referred 
works do not make reference to the definition of the ageing cycles based on existing standard procedures.

Freeze-thaw is one of the degradation mechanisms that will cause the most severe damages in mortars. As such, several authors analysed this degradation mechanism and the related damages in mortars.

Puertas et al. [7] found that mortars incorporating activated slags present higher stability to freeze-thaw action, increasing their mechanical resistance, compared to mortars incorporating fly ash or cement. The inclusion of polypropylene fibres did not promote an improvement in performance after the accelerated ageing cycles. Degirmenci, Yilmaz [8] verified that the addition of $10-15 \%$ of diatomite (in replacement of cement) increased the compressive strength after freeze-thaw cycles. This fact could be a result of the filler diatomite effect on the mortar. On the contrary, Bocca, Grazzini [34] verified a decrease in compressive strength after ageing. According to ČSN 722452 [35], Vejmelková et al. [9] classified the different samples as being resistant or not to freezing. Only the lime-metakaolin based mortar, with higher purity, and a commercial mortar were classified as freeze-resistant. Wang, Meyer [36] found that when performing the accelerated ageing procedure defined in ASTM C666/C666M-03 [37] to mortars with different percentages of high impact polystyrene addition, the dynamic modulus did not change, even after 300 cycles of ageing. Ferrándiz-Mas, García-Alcocel [33] verified that the addition of EPS improved or maintained the durability of the mortar, since the EPS absorbs some of the crystallisation pressure of the ice, contributing to the reduction of damages. Di Bella et al. [38] obtained, as expected, a reduction in mechanical strength, especially in the flexural strength, after accelerated ageing, for the evaluated three types of lime-based mortars: with the addition of polypropylene, sisal and kenaf fibres. This resistance decrease can be explained by the action of the absorbed water that freezes when subjected to low temperature, increasing in volume within the pores. That fact produces cracking and loss of cohesion in the 
mortar. The thermal shocks and the action of the infrared radiation did not promote significant changes in the specimens during the heat-cold cycles, being the main cause of degradation the freeze-thaw cycles. This was owed to the humidification and subsequent action of negative temperatures with the formation of ice. Hannawi, Prince-Agbodjan [10] found that after the freeze-thaw cycles the mechanical strength decreased, which may be due to the degradation of the specimens owing to cracking and emergence of voids.

A study of the evaluation of the durability of ETICS, through service life prediction, is presented by Norvaišiene et al. [39] that performed an accelerated rain-cold-heat ageing cycle for this purpose. The presented cycle was intended to reproduce the real effect of one-year climate exposure during 16 days. Therefore, the experimental results were evaluated after 16 and 32 days, simulating 1 and 2 years of ageing, respectively. It was found that increasing the thickness of the glass fibre mesh allows an improvement in impact strength, but also leads to the increase of the moisture content of the outer layer of the system.

\section{MATERIALS AND METHODS}

The experimental methodology consists in assessing commercial thermal rendering/plastering systems (already in use by the construction industry) by adapting existing methodologies, such as the ones envisaged in EN 1015-21 and ETAG 004, using small-scale specimens. The EN 1015-21 methodology includes heating-freezing (HF) and humidificationfreezing (HumF) ageing cycles and the ETAG 004 freeze-thawing (FT) cycles. The evaluation of the existing procedures allows understanding the gaps, disadvantages and advantages of implementing such methodologies to thermal rendering and plastering systems.

The methodologies defined in EN 1015-21 and in ETAG 004 were adapted to the thermal systems under study, considering a typical constitution, according to each manufacturers' conditions. As such, the detailed knowledge of the materials formulations is not available owing 
to industrial confidentiality. The evaluation of products/systems that are available in the market has the aim to contribute to filling the gap in terms of durability assessment of this type of multilayer systems. Hence, the constitution of the three studied systems is presented in Table 2 . Generally, the systems (S) comprised 2/3 main layers: thermal mortar (TR), finishing render (C) and/or finishing coating (C), from inside to outside. All specimens were applied on ceramic brick masonry. S1 test specimen has an area of $40 \times 60 \mathrm{~cm}^{2}$ and $\mathrm{S} 2$ and $\mathrm{S} 3$ are $50 \times 50 \mathrm{~cm}^{2}$. $\mathrm{S} 1$ is tested with two different finishing coatings: an organic coating (S1-O) and a mineral coating (S1-M). The constitution and cross-section of the studied systems are shown in Electronic Supplementary Material SM1.

Table 2. Constituent materials of the studied thermal rendering and plastering systems.

\begin{tabular}{|c|c|c|c|c|}
\hline System & Material & Binders & Aggregates & Layer properties \\
\hline \multirow{4}{*}{$\mathrm{S} 1$} & TR1 & Lime & EPS & $\begin{array}{c}4+2 \mathrm{~cm} \text { (glass fibre mesh } \\
\text { between the layers) }\end{array}$ \\
\hline & $\mathrm{C} 1$ & $\begin{array}{c}\text { Natural hydraulic lime, cement, } \\
\text { pozzolans and polymers }\end{array}$ & $\begin{array}{l}\text { Mineral fillers, synthetic } \\
\text { fibres and resins }\end{array}$ & $\begin{array}{c}\approx 4 \mathrm{~mm} \text { (glass fibre mesh } \\
\text { in the render) }\end{array}$ \\
\hline & $\mathrm{S} 1-\mathrm{O}$ & $\begin{array}{l}\text { Mineral fillers, acrylic resins in } \\
\text { and specific additives (a }\end{array}$ & $\begin{array}{l}\text { queous dispersion, pigments, } \\
\text { tifungals and others) }\end{array}$ & \multirow{2}{*}{1 to $2 \mathrm{~mm}$} \\
\hline & S1-M & $\begin{array}{c}\text { Natural hydraulic lime and } \\
\text { pozzolans binder }\end{array}$ & $\begin{array}{l}\text { Mineral fillers, pigments, and } \\
\text { specific additives }\end{array}$ & \\
\hline \multirow{3}{*}{$\mathrm{S} 2$} & TR2 & White cement and hydrated lime & EPS & $2 \mathrm{~cm}$ \\
\hline & $\mathrm{C} 2$ & Hydraulic binders & $\begin{array}{l}\text { Mineral fillers, synthetic } \\
\text { fibres and resins }\end{array}$ & $\begin{array}{c}\approx 3 \mathrm{~mm} \text { (glass fibre mesh } \\
\text { in the render) }\end{array}$ \\
\hline & Coating & $\begin{array}{r}\text { Silicate based aqueous painting: } \\
\text { pigments and sp }\end{array}$ & $\begin{array}{l}\text { ootassium silicates, inorganic } \\
\text { cific additives }\end{array}$ & 1 to $2 \mathrm{~mm}$ \\
\hline \multirow{2}{*}{$\mathrm{S} 3$} & TR3 & Gypsum & Cork & $2 \mathrm{~cm}$ \\
\hline & $\mathrm{C} 3$ & Gypsum & Mineral fillers & $\approx 2 \mathrm{~mm}$ \\
\hline
\end{tabular}

Thermal rendering systems (S1 and S2) were tested by adapting the methodology defined in EN 1015-21 (HF+HumF), while S3 was evaluated by implementing the heating-freezing (HF) ageing only. S1 and S2 were also evaluated according to the ageing procedures defined in ETAG 004 (freeze-thaw), applicable to small-scale samples. Each procedure was implemented separately in different specimens. Both ageing procedures are described in 2.2.

The heating procedure was performed by using an Infra-Red (IR) lamp device (2000 W), while the freezing required the use of a deep-freeze cabinet. Regarding the 
humidification/thawing step, a large waterproof container was used to keep the rendered surface below a minimum $15 \mathrm{~mm}$ water depth.

The ageing effect and the correlation between the test results and the action of the degradation mechanisms occurring in practice were analysed. To do so, liquid water permeability, adhesive strength, impact resistance and microstructure were evaluated before and after the ageing procedures. The liquid water permeability was determined through two distinct methodologies. One of the methods is based on the water permeability test described in EN 1015-21, which measures the liquid water required to keep a permanent $100 \mathrm{~mm}$ head of water above the rendered surface, using a cone with $100 \mathrm{~mm}$ diameter. The cone is bonded to the surface using a water-resistant sealant. The amount of water necessary to keep the water level constant $(100 \mathrm{~mm})$ over $48 \mathrm{~h}$ is registered. The other method is performed using three vertically applied L-shaped Karsten tubes. The tube has volume graduation, where $10 \mathrm{ml}$ correspond to a $10 \mathrm{~cm}$ head of water. After bonding the three tubes to the rendered surface, each tube is filled with water until $10 \mathrm{~mm}(0 \mathrm{ml}$ scaling $)$ and the drop in the water level is recorded at regular intervals. The test equipment used to determine the liquid water permeability is demonstrated in Electronic Supplementary Material SM2.

The adhesive strength was performed based on EN 1015-12 [40]. The test was carried out using a testing machine - Proceq DY-216 - to apply the tensile load using a square pull-head (50x50 mm) glued, with epoxy resin, to the test area (5 measurements per specimen). Despite the EN 1015-12 indicating circular pull-heads, the test was performed using square pull-heads, due to the high disturbance of the core drilling machine and the lower strength of the thermal mortars.

The resistance to impact was determined by the guided fall of two steel balls with two different impact energies (2J and 10J), based on the EN13497 [41]. Three impacts using the two steel balls were performed. 
The microstructure was observed using the optical microscope Olympus SZH10.

\section{ACCELERATED AGEING - EXPERIMENTAL RESULTS}

\subsection{Water permeability}

Since the thermal mortars generally present higher water absorption compared with common insulation materials, such as EPS (almost impermeable), the exterior layers (finishing coating+finishing render) proved to have a relevant impact in the durability of the inner layers, acting as a barrier. In that way, the durability assessment should take into account the entire system and the more relevant properties of the materials to each ageing procedure that they are subjected to. Table 3 presents the effect of the different ageing procedures (before ageing (BA), after heat-freezing+humidification-freezing (HF+HumF) and after freeze-thawing (FT)), regarding the water permeability.

Table 3. Average volume of water penetration before (BA) and after (AA) the tested ageing procedures.

\begin{tabular}{|c|c|c|c|c|c|c|c|c|c|}
\hline \multirow{2}{*}{\multicolumn{2}{|c|}{$\begin{array}{c}\text { Ageing procedure } \\
\begin{array}{c}\text { Experimental } \\
\text { method }\end{array} \\
\end{array}$}} & \multicolumn{4}{|c|}{$\mathrm{HF}+\mathrm{HumF}$} & \multicolumn{4}{|c|}{ FT } \\
\hline & & \multicolumn{2}{|c|}{ Cone } & \multicolumn{2}{|c|}{ Karsten } & \multicolumn{2}{|c|}{ Cone } & \multicolumn{2}{|c|}{ Karsten } \\
\hline $\mathrm{Vt}(\mathrm{r}$ & & $24 \mathrm{~h}$ & $48 \mathrm{~h}$ & $1 \mathrm{~h}$ & $2 \mathrm{~h}$ & $24 \mathrm{~h}$ & $48 \mathrm{~h}$ & $1 \mathrm{~h}$ & $2 \mathrm{~h}$ \\
\hline \multirow{2}{*}{$\mathrm{S} 1-\mathrm{O}$} & $\mathrm{BA}$ & 44.6 & 89.1 & 99.0 & 141.5 & 44.6 & 89.1 & 99.1 & 141.5 \\
\hline & $\mathrm{AA}$ & 191.0 & 216.5 & 292.4 & 386.7 & 31.8 & 50.9 & 146.2 & 330.1 \\
\hline \multirow{2}{*}{ S1-M } & $\mathrm{BA}$ & 802.1 & 1228.7 & 188.6 & 334.8 & 802.1 & 1228.7 & 188.6 & 334.8 \\
\hline & $\mathrm{AA}$ & 1082.3 & 1171.4 & 980.9 & 1626.9 & 184.6 & 210.1 & 245.2 & 396.1 \\
\hline \multirow{2}{*}{$\mathrm{S} 2$} & $\mathrm{BA}$ & 445.6 & 687.5 & 202.8 & 292.4 & 445.6 & 687.5 & 202.8 & 292.4 \\
\hline & $\mathrm{AA}$ & 420.2 & 573.0 & 268.8 & 367.8 & 86.6 & 140.1 & 183.9 & 226.4 \\
\hline \multirow{2}{*}{$\mathrm{S} 3$} & $\mathrm{BA}$ & 636.6 & 3934.3 & 6224.7 & - & - & - & - & - \\
\hline & $\mathrm{AA}$ & 2323.7 & 7754.0 & 26714.5 & - & - & - & - & - \\
\hline
\end{tabular}

*Due to the fast water absorption, S3 measurements with the cone method were made after $1 \mathrm{~h}$ and $5 \mathrm{~h}$, rather than $24 \mathrm{~h}$ and $48 \mathrm{~h}$, respectively.

Regarding the obtained results, the amount of water that penetrates into the specimen increases after ageing procedures. As expected, S3 presents a much higher water absorption volume than S1 and S2, presenting a higher variation after heating-freezing ageing cycles 
( $265 \%$ and $97 \%$ variation with the cone method after $24 \mathrm{~h}$ and $48 \mathrm{~h}$, respectively). The effect of water in gypsum-based materials promotes cracking and loss of the finishing plaster material (C3), which allowed the inner layer (thermal plaster) becoming visible. This is due to the intrinsic properties of gypsum, which has high capillary absorption and dissolves in water $[42,43]$. Another clear finding is the difference between the organic and the mineral coating, as the latter presents a much higher water absorption. Regarding the data provided by the manufacturer, the organic coating is less permeable than the mineral coating, since it is classified as W3 $\left(\leq 0.1 \mathrm{~kg} / \mathrm{m}^{2} \cdot \mathrm{h}^{0.5}\right)$, according to EN 15824 [44], while the mineral coating has a W2 classification $\left(<0.2 \mathrm{~kg} / \mathrm{m}^{2} \cdot \mathrm{min}^{0.5}\right)$, according to EN 998-1 [11]. S1 and S2 thermal rendering systems present a distinct behaviour after ageing, as can be seen in Fig. 1. S1-M presents a faster increase in water absorption than the rest of the specimens, which show a constant increase (similar slope). A high correlation $\left(\mathrm{R}^{2}>0.95\right)$ between the absorbed water volume and the square root of time is observed. However, the cone method presented higher variation and, consequently, lower correlations in general. This could be related to the higher complexity of the cone test method, which introduces higher variability in the results, comparing to the Karsten tubes method. The use of three Karsten tubes also allows evaluating different areas of the system. This fact is of great importance since thermal mortars do not present a homogenous constitution (regarding the porosity and different pore size distribution). Apparently, the cone method is more suitable to determine the permeability of low absorption materials that combined with the higher pressure than the Karsten tubes, make this test procedure inadequate to thermal rendering systems. 


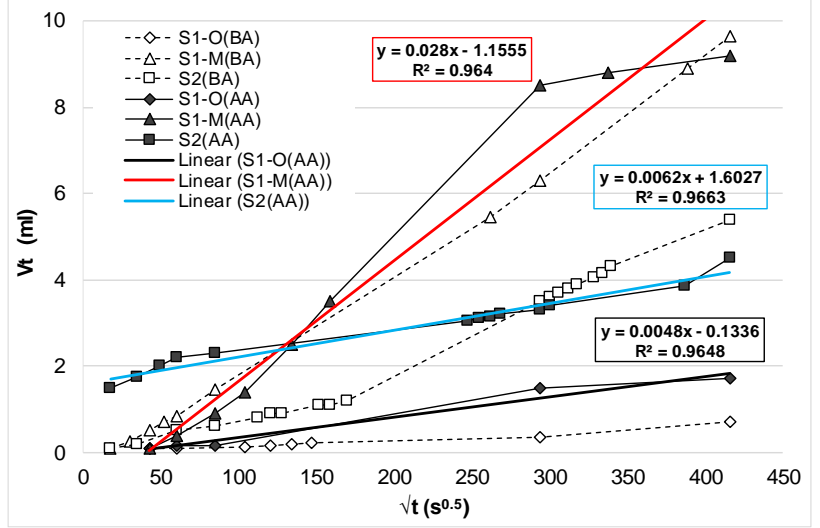

a)

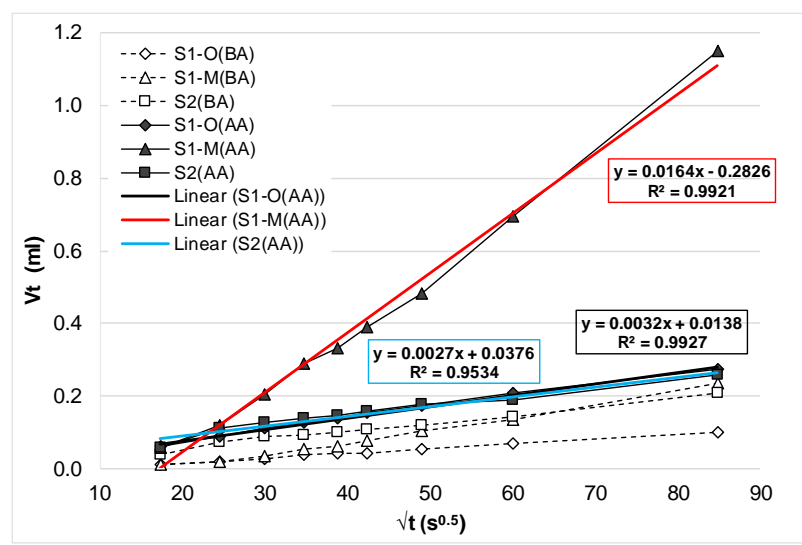

b)

Fig. 1. Water permeability test results using the: a) Cone method; b) Karsten tubes method.

\subsection{Adhesive strength}

Fig. 2 shows the influence of the different ageing procedures in the adhesive strength of the analysed thermal systems.

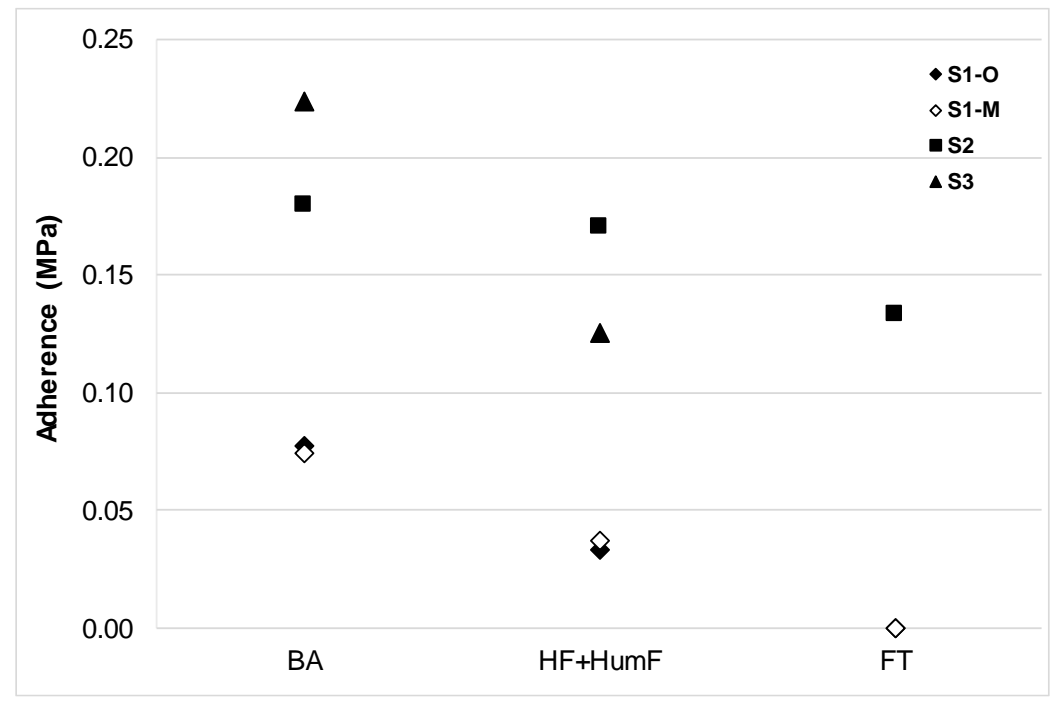

Fig. 2. Adhesive strength of the thermal systems, before and after the ageing procedures.

A decrease in the adhesive strength after ageing is observed in all the studied systems. Regarding the results obtained in S1-O and S1-M, before ageing, the resistance is similar for both coatings. Moreover, the application of 2 layers of thermal render and glass fibre mesh introduces an interface where the fracture could occur, as observed in Fig. 3 a) and b) (the 
fracture occurs between the two layers of thermal mortar $(4 \mathrm{~cm}+2 \mathrm{~cm})$ where the reinforced fibre mesh was applied). This adhesive rupture is observed in $50 \%$ and $75 \%$ of the cases, for organic and mineral coatings, respectively. Observing Fig. 2, when this rupture occurs, the adhesive strength is considerably lower than the observed in S2 and S3 (where cohesive ruptures are dominant). Representative cohesive fracture patterns, obtained in S2 and S3, are shown in Electronic Supplementary Material SM3. In that way, the glass fibre mesh should be well embedded in the thermal render to minimise the interface effect. All these aspects contribute to a decrease in the adhesive strength of S1. S1-O and S1-M presented very low adhesive strength, after ageing, and the adhesive fractures (between the thermal render and the mesh interface) occurred more frequently. This fact was systematically observed regarding the different systems (considering the five measurements). In addition, the adhesive strength in $\mathrm{S} 1$, for both coatings in the five measurements, was 0 using FT ageing. S2 also presents a low standard deviation (around $0.02 \mathrm{MPa}$ ) in both ageing procedures. Despite the short ageing period, the heating-freezing (HF) cycles produce a quite significant decrease of the adhesive resistance (around 78\%) in S3. This states the importance of an accurate analysis of the durability in all the systems, even in less severe environments (indoor application), without liquid water action (humidification procedure).

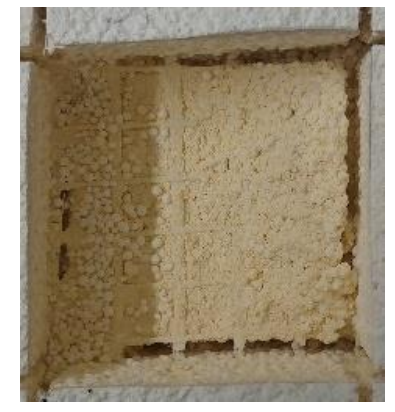

a)

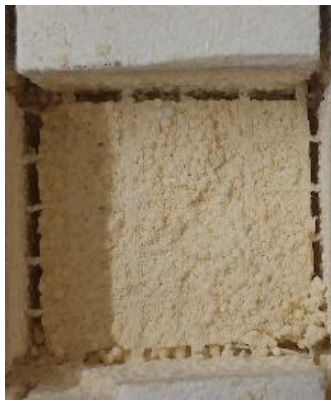

b)

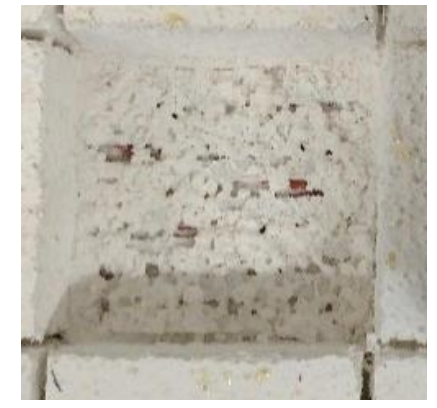

c)

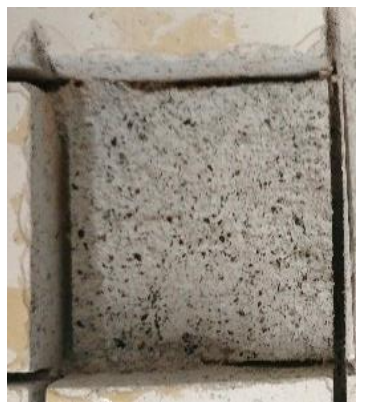

d)

Fig. 3. Obtained samples of adherence tests after HF+HumF in: a) S1-O; b) S1-M; c) S2; d)

S3. 
The adhesive strength after freeze-thaw ageing cycles presents a specific behaviour regarding S1. As it can be seen in Fig. 4, the fractures were mostly adhesive between the thermal render and the finishing render. The severe ageing cycles promote a fast detachment of the layers (at the pre-cut phase) and the embrittlement of the thermal render. The adhesive fracture pattern obtained in S1, after FT ageing cycles, is shown in Electronic Supplementary Material SM4. S2 presents a decrease of around $35 \%$ in the adhesive strength, after ageing, and the cohesive fractures in the thermal render itself occurred with a higher rate (89\%) than the adhesive fractures between the thermal render and the substrate.

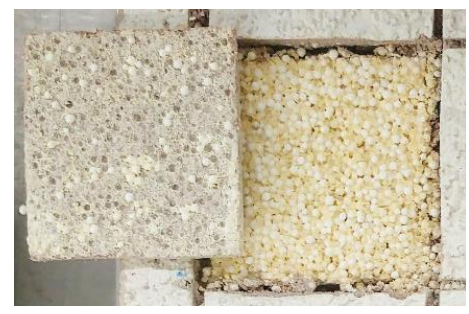

a)

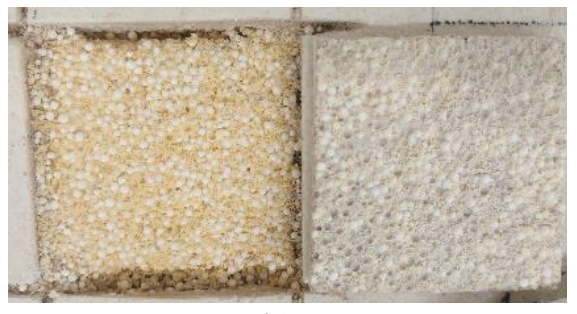

b)

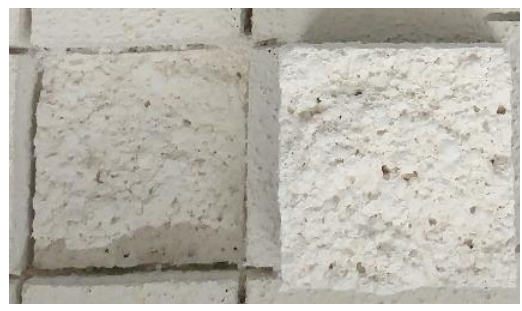

c)

Fig. 4. Obtained samples of adherence tests after FT in: a) S1-O; b) S1-M; c) S2.

\subsection{Impact resistance}

Generally, the dent diameter increases after ageing. However, that decrease is not significant $(\approx 5 \%)$, and the precision of the measurements (in millimetres) introduces some variability. As such, a qualitative analysis by means of observed damages was performed. The thermal rendering systems present, in general, more damages after ageing procedures, such as cracking and detachment. Regarding the organic and mineral coatings influence in the impact resistance, a distinct behaviour is noted. The organic coating presents larger cracks and complete perforation, especially with $10 \mathrm{~J}$ energy impact. The mineral coating does not allow perforation (finishing render not visible), resulting in microcracks. However, higher depressions, detachment and loss of material are observed with the mineral coating. The existence of resins in the organic coating could contribute to increasing the system resistance, decreasing the depressions. However, the cracking generally occurs throughout the coating 
thickness, which allows a faster water penetration in the inner layers of the system. In addition, the FT ageing procedure promotes larger dents in $\mathrm{S} 1$ than the $\mathrm{HF}+\mathrm{HumF}$, evidencing higher ageing severity of the freeze-thaw degradation mechanism. S2 presents a significant degradation after ageing, in terms of qualitative observation, such as delamination of the finishing coating, more evident with 10J energy impact. S3 presented delamination of the finishing plaster (C3) before and after ageing, becoming visible the thermal render (grey colour). The visual observation of a representative dent, before and after ageing, is shown in Electronic Supplementary Material SM5 and SM6.

\subsection{Pore structure and visual observation}

The heating-freezing and humidification-freezing cycles produced an alteration on the matrix of the thermal render. The water penetration and consequent freeze-thaw action promoted the material expansion and contraction, producing cracks among macropores. In addition, the water action may lead to some loss of binder. Regarding the binder matrix, it is possible to observe the enclosed porosity, in the thermal render with organic coating, while with the mineral coating, some open pores are visible (see Fig. 5). Also, the presence of water is stronger in the TR with the mineral coating, due to matrix alteration. This is in accordance with the results obtained in the liquid water permeability, which shows to be higher with the mineral than with the organic coating. 


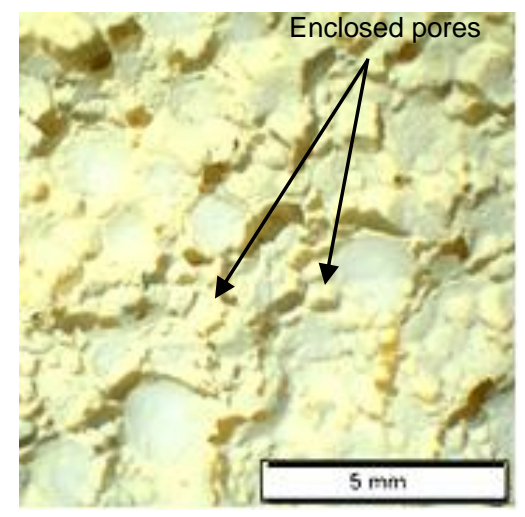

a)

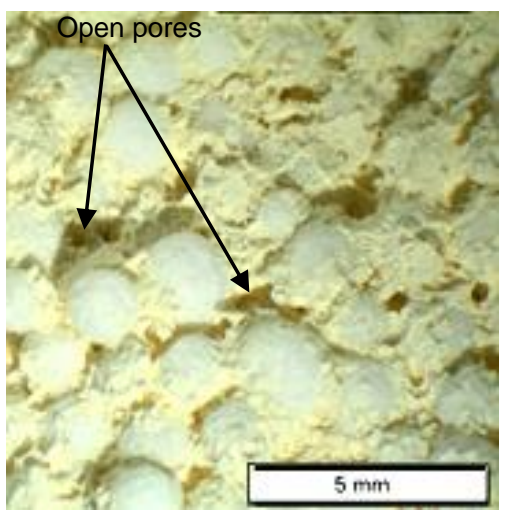

b)

Fig. 5. Optical microscope images after HF+HumF in the thermal render of: a) S1-O; b) S1-

M.

The freeze-thawing ageing promoted higher degradation of the samples, as already referred. This could be related to the higher severity of FT, but also some particularities of the testing procedure. Damages in the coatings were observed, which may be related to the handling of the specimens during the ageing in the different procedures (freezing and thawing), performed in different equipment. Beyond the coating observation, cracks were found in the sealant placed in the sides of the specimen. This fact could be attributed to the temperature variations during the cycles, which also affect the sealant. These two damages allow the water to easily penetrate in the inner layers (finishing render and thermal render) resulting in a severe deterioration of the system, such as the adhesive fractures and the embrittlement of the thermal render. The degradation of the thermal rendering systems may be distorted by these specific damages, resulting in overstated action. The referred damages are shown in Electronic Supplementary Material SM7.

\subsection{Discussion}

The experimental tests carried out to evaluate the durability of the thermal mortars, and related systems allow to identify several problems and constraints with the testing operation itself. Regarding the liquid water permeability tests, the porous constitution and high absorption of the thermal renders do not allow reliable results with the cone method, since they present a 
great amount of water diffusion by the surface. The Karsten tubes method consists of a quick and easy way of measuring the liquid water permeability under low pressure allowing more consistent results. Additionally, the possibility of measurement in a vertical position allows the testing of wall specimens, where the cone method cannot be implemented. Concerning the adhesive strength, the execution of circular pre-cuts invalidated the test, since the circular frequency of the drilling machine pulls out the specimen before pull-off application. In that way, square pre-cuts were performed in order to enable the test. Studies on the effect of the precut type showed similar results for circular and square pre-cuts $[45,46]$. This is a relevant test since it allows assessing the connection between the materials [47]. The observed damages in the coatings may be related to the handling of the specimens during the ageing in the different procedures (freezing and thawing), performed in different equipment. In addition, the observed cracks in the sealant, placed in the sides of the specimen, could be attributed to the temperature variations during the cycles, which also affect the sealant durability. As such, the degradation of the thermal rendering systems may be distorted by these specific damages, resulting in overstated action.

Also, the configuration of the specimen demonstrated a significant impact on the mechanical behaviour. The execution of the specimens as the systems are applied on-site was considered of major importance since different configurations of the same systems led to different results. This fact was also verified by Torres et al. [48], highlighting the influence of the substrate characteristics (such as the porosity and the water absorption) on the properties of the mortars. The application of 2 layers of thermal render and glass fibre mesh introduces an interface where the fracture could occur (which was verified). In that way, the glass fibre mesh should be well embedded in the thermal render to minimise the interface effect. Despite the easier production of the small-size samples, such as the ones used in the existing methodologies, more variability that may distort the results is introduced. On one hand, the need for sealing the 
sides of the specimens and their handling during the different ageing procedures (such as the freezing-thawing) increases the risk of damaging the thermal rendering system layers. That fact may distort the results, overstating the damages. On the other hand, the small-scale samples allow a quicker activation of the degradation mechanisms, such as the freeze-thawing. The materials are permanently submitted to the direct water action, which does not happen in the real-scale specimens (wall). However, a faster ageing by intensifying the degradation agents may activate other degradation mechanisms, distorting the expectable degradation.

The accelerated ageing cycles envisaged in the existing procedures gave a great amount of information that allowed the definition of the durability assessment methodology directly applicable to thermal rendering and plastering systems [49]. The freeze-thaw cycles are more severe than the heating-freezing/humidification-freezing cycles, since, in general, the pore structure presents higher damages, observed by the decrease in the mechanical resistance. The higher number of cycles and the severity of the freeze-thaw ageing cycles may reproduce the effect of colder climates (like the northern European countries). The heatingfreezing/humidification-freezing cycles combine degradation mechanisms, which occur in several locations, mainly in south European countries, owing to the high heating temperature.

After the different ageing procedures, the specimens generally presented an alteration of the matrix, an increase of the water permeability and a decrease of the mechanical strength. The water penetration and consequent freeze-thaw action promote material expansion and contraction, breaking the several macropores. The mineral coating showed higher water absorption than the organic coating, highlighting the importance of assessing durability while considering the different components of the thermal rendering systems. The effect of water in gypsum-based materials promoted cracking and loss of the finishing plaster, due to the intrinsic properties of gypsum, which has high capillary absorption and dissolves in water. The low 
mechanical strength of the thermal rendering and plastering systems highlighted the importance of carefully analysing the zones where these systems could be applied.

In summary, a complete durability assessment methodology should take into account and reproduce the most relevant degradation mechanisms in thermal rendering and plastering systems, such as the freeze-thawing and/or temperature fluctuation. The ageing procedures in small-scale samples allow the implementation of specific procedures, which may complement other relevant ageing procedures performed in large samples (walls).

\section{CONCLUSIONS}

The existing durability methodologies applicable to renders and thermal multi-layer systems (ETICS) are suitable to be adapted to thermal rendering and plastering systems since they present some similar characteristics. This adaptation allowed collecting reliable data and inputs to the development of durability assessment methodologies directly applicable to thermal rendering and plastering systems. The analysis consisted of testing small-scale samples to heating-freezing + humidification-freezing and freeze-thawing ageing procedures and allowed identifying several constraints related to the experimental procedures. Namely, the handling of the specimens during the ageing procedures and consequent damages in the coating and sealant were observed. This fact allowed a quicker degradation of the thermal systems promoted by an easier penetration of the degradation agents in the inner layers. Also, both methods $(\mathrm{HF}+\mathrm{HumF}$ and FT) allowed the activation of the most relevant degradation mechanisms in thermal rendering and plastering systems, such as the freeze-thawing and temperature fluctuation. The higher number of cycles and the observed severity of the freeze-thaw ageing cycles, according to ETAG 004, may reproduce the effect of the northern European climates, while the heatingfreezing/humidification-freezing cycles, described in EN 1015-21, combine degradation mechanisms that occur in central and southern European climates. In that way, the freeze- 
thawing ageing is adequate to evaluate the degradation in colder climates. Considering that in warmer climates the absorbed water evaporates before very low temperatures occur, the freezethawing degradation is not expectable to occur. However, in moderate climates that evaporation does not occur as fast as in warm climates. As such, since thermal renders have higher water absorption than a common insulation (such as EPS) the freezing may occur.

In conclusion, the analysis of the accelerated ageing cycles envisaged in the standardised procedures provided a great amount of information to increase the knowledge about the durability of thermal mortars, directing its evaluation to an adequate methodology and experimental procedures.

\section{ACKNOWLEDGEMENTS}

The authors acknowledge to Saint-Gobain Weber, Secil Argamassas and Sival - Gessos Especiais to the materials supply.

\section{COMPLIANCE WITH ETHICAL STANDARDS:}

Funding: This work was financially supported by Project PTDC/ECI-CON/28766/2017 POCI-01-0145-FEDER-028766 funded by FEDER funds through COMPETE2020 - Programa Operacional Competitividade e Internacionalização (POCI) and by national funds (PIDDAC) through FCT/MCTES and the Project Reuse - Rehabilitation and Sustainability, supported by LNEC. This work was financially supported by: UID/ECI/04708/2019- CONSTRUCT Instituto de I\&D em Estruturas e Construções funded by national funds through the FCT/MCTES (PIDDAC). The first author would like to acknowledge the support of FCT Fundação para a Ciência e a Tecnologia, the funding of the Doctoral Grant PD/BD/52659/2014, through the Doctoral Programme EcoCoRe.

Conflict of Interest: The authors declare that they have no conflict of interest. 


\section{REFERENCES}

1. van Breugel K (2018) How models can make a difference for a sustainable future of the building industry. Materials and Structures/Materiaux et Constructions 51 (6). doi:10.1617/s11527-018-1287-8

2. Esmaeeli HS, Farnam Y, Bentz DP, Zavattieri PD, Weiss WJ (2017) Numerical simulation of the freeze-thaw behavior of mortar containing deicing salt solution. Materials and Structures/Materiaux et Constructions 50 (1). doi:10.1617/s11527-016-0964-8

3. Thomson M, Erik Lindqvist J, Elsen J, Groot C (2007) Chapter 2.5 Characterisation: Porosity of mortars.

4. Coutinho MJÁRdS (1998) Improvement of Concrete Durability by Formwork Treatment. University of Porto, Porto

5. Concrete Society (1987) Permeability Testing of Site Concrete. A review of methods and experience. Techical Report.

6. Gomes MG, Flores-Colen I, Melo H, Soares A (2019) Physical performance of industrial and EPS and cork experimental thermal insulation renders. Construction and Building Materials 198:786-795. doi:https://doi.org/10.1016/j.conbuildmat.2018.11.151

7. Puertas F, Amat T, Fernández-Jiménez A, Vázquez T (2003) Mechanical and durable behaviour of alkaline cement mortars reinforced with polypropylene fibres. Cement and Concrete Research 33 (12):2031-2036. doi:http://dx.doi.org/10.1016/S0008-8846(03)00222-9

8. Degirmenci N, Yilmaz A (2009) Use of diatomite as partial replacement for Portland cement in cement mortars. Construction and Building Materials 23 (1):284-288. doi:10.1016/j.conbuildmat.2007.12.008

9. Vejmelková E, Keppert M, Keršner Z, Rovnaníková P, Černý R (2012) Mechanical, fracturemechanical, hydric, thermal, and durability properties of lime-metakaolin plasters for renovation of historical buildings. Construction and Building Materials 31:22-28. doi:10.1016/j.conbuildmat.2011.12.084

10. Hannawi K, Prince-Agbodjan W (2015) Transfer behaviour and durability of cementitious mortars containing polycarbonate plastic wastes. European Journal of Environmental and Civil Engineering 19 (4):467-481. doi:10.1080/19648189.2014.960100

11. CEN (2010) EN 998 Specification for mortar for masonry. Part 1: Rendering and plastering mortar. European Commitee for Standardization, Brussels

12. CEN (2002) EN 1015 Methods of test for mortar for masonry. Part 21: Determination of the compatibility of one-coat rendering mortars with substrates. European Commitee for Standardization, Brussels

13. ISO (2011) ISO 15686 Buildings and constructed assets - Service life planning. Part 1: General principles and framework.

14. Batchelor AW, Loh NL, Chandrasekaran M (2011) Materials Degradation and its Control by Surface Engineering

15. Addleson L (1992) Buildings Failures: A Guide to Diagnosis, Remedy and Prevention. 3rd edn. Butterworth Architecture, Oxford, England

16. Aguiar J, Cabrita A, Appleton J (2002) Support Guide to the rehabilitation of residential buildings (Guia de apoio à reabilitação de edifícios residenciais), vol 1 and 2. Lisboa

17. Palomo A, Blanco-Varela MT, Martinez-Ramirez S, Puertas F, Fortes C (2000) Historic Mortars: Characterization and Durability. New Tendencies for Research Paper presented at the Proceedings 9th International Congress on Deterioration and Conservation of Stone, Venice, 19-24 June 2000

18. van Hees R, Veiga R, Sližková Z (2017) Consolidation of renders and plasters. Materials and Structures/Materiaux et Constructions 50 (1). doi:10.1617/s11527-016-0894-5 
19. Pavía S, Treacy E (2006) A comparative study of the durability and behaviour of fat lime and feebly-hydraulic lime mortars. Materials and Structures/Materiaux et Constructions 39 (287):391-398. doi:10.1617/s11527-005-9033-4

20. Flores-Colen I, Brito Jd, Freitas V Diagnosis and maintenance techiques for stain removal in rendered walls. In: APFAC (ed) I National Congress on Construction Mortars Lisbon, 2005. pp 24-25

21. CEB (1992) Durable Concrete Structures. Design Guide, vol Bulletin d'Information Thomas Telford

22. Sousa V, Pereira FD, Brito Jd (2005) Traditional Renders: Main Causes of Degradation. Engenharia Civil, vol 23 Minho University. Civil ENgineering Department,

23. Borges C, Santos Silva A, Veiga R (2014) Durability of ancient lime mortars in humid environment. Construction and Building Materials 66:606-620. doi:http://dx.doi.org/10.1016/j.conbuildmat.2014.05.019

24. Fragata A, Rosário Veiga M, Velosa A (2016) Substitution ventilated render systems for historic masonry: Salt crystallization tests evaluation. Construction and Building Materials 102:592-600. doi:https://doi.org/10.1016/j.conbuildmat.2015.10.130

25. do Rosário Veiga M, Fragata A, Velosa AL, Magalhães AC, Margalha G (2010) LimeBased Mortars: Viability for Use as Substitution Renders in Historical Buildings. International Journal of Architectural Heritage 4 (2):177-195. doi:10.1080/15583050902914678

26. Franzoni E, Gentilini C, Santandrea M, Zanotto S, Carloni C (2017) Durability of steel FRCM-masonry joints: effect of water and salt crystallization. Materials and Structures/Materiaux et Constructions 50 (4). doi:10.1617/s11527-017-1070-2

27. Gonçalves de Carvalho C, Flores-Colen I, Faria P (2015) Rehabilitation of renders of old buildings in Portugal: Survey, supporting methodology proposal and case study. Structural Survey 33 (4/5):337-353. doi:doi:10.1108/SS-04-2015-0024

28. CSA (1995) CSA S478-95: Guideline on Durability in Buildings. CSA, Canada

29. EOTA (1999) Assessment of working life of products. Guidance Document 003. European Organisation for Technical Approvals, Brussels

30. Maia J, Ramos NMM, Veiga R (2018) Evaluation of the hygrothermal properties of thermal rendering systems. Building and Environment 144:437-449. doi:https://doi.org/10.1016/j.buildenv.2018.08.055

31. EOTA (2013) ETAG 004. Guideline for European Technical Approval of External Thermal Insulation Composite Systems with Rendering. European Organisation for Technical Approvals, Brussels

32. Gonçalves da Silva M (2004) Influence of Environmental Aging on Properties of Polymeric Mortars. Journal of Materials in Civil Engineering 16 (5):461-468. doi:10.1061/(ASCE)08991561(2004)16:5(461)

33. Ferrándiz-Mas V, García-Alcocel E (2013) Durability of expanded polystyrene mortars. Construction and Building Materials 46:175-182. doi:10.1016/j.conbuildmat.2013.04.029

34. Bocca P, Grazzini A (2012) Mechanical Properties and Freeze-Thaw Durability of Strengthening Mortars. Journal of Materials in Civil Engineering 25 (2):274-280. doi:10.1061/(ASCE)MT.1943-5533.0000597

35. ČSN (1968) ČSN 722452 - Testing of frost resistance of mortar. . Czech standard,

36. Wang R, Meyer C (2012) Performance of cement mortar made with recycled high impact polystyrene. Cement and Concrete Composites 34 (9):975-981. doi:http://dx.doi.org/10.1016/j.cemconcomp.2012.06.014

37. ASTM (2008) Standard Test Method for Resistance of Concrete to Rapid Freezing and Thawing. ASTM International, United States of America 
38. Di Bella G, Fiore V, Galtieri G, Borsellino C, Valenza A (2014) Effects of natural fibres reinforcement in lime plasters (kenaf and sisal vs. Polypropylene). Construction and Building Materials 58:159-165. doi:http://dx.doi.org/10.1016/j.conbuildmat.2014.02.026

39. Norvaišiene R, Griciute G, Bliudžius R, Ramanauskas J (2013) The changes of moisture absorption properties during the service life of external thermal insulation composite system. Medziagotyra 19 (1):103-107. doi:10.5755/j01.ms.19.1.3834

40. CEN (2000) EN 1015 Methods of test for mortar for masonry. Part 12: Determination of adhesive strength of hardened rendering and plastering mortars on substrates. European Commitee for Standardization, Brussels

41. CEN (2002) EN 13497 Thermal insulation products for building applications Determination of the resistance to impact of external termal insulation composite systems (ETICS). European Commitee for Standardization, Brussels

42. Klimchouk A (2000) Dissolution and conversions of gypsum and anhydrite.

43. Hong D, Fan M, Yu L, Cao J (2018) An experimental study simulating the dissolution of gypsum rock. Energy Exploration \& Exploitation 36 (4):942-954. doi: $10.1177 / 0144598717751927$

44. CEN (2017) EN 15824 Specifications for external renders and internal plasters based on organic binders. European Commitee for Standardization, Brussels

45. Costa E, Carasek H, Cascudo O, Almeida S (2007) Evaluation of brasilian test method for the adhesive strength determination of renders Paper presented at the II National Congress on Construction Mortars, Lisbon, 22-23 November

46. Gonçalves S (2004) Variability and dispersion factor of adhesive strength of renders - Case study. University of Brasília, Brasília

47. Botas S, Veiga R, Velosa A (2017) Bond strength in mortar/ceramic tile interface - testing procedure and adequacy evaluation. Materials and Structures/Materiaux et Constructions 50 (5). doi:10.1617/s11527-017-1086-7

48. Torres I, Veiga R, Freitas V (2018) Influence of Substrate Characteristics on Behavior of Applied Mortar. Journal of Materials in Civil Engineering 30 (10):04018254. doi:doi:10.1061/(ASCE)MT.1943-5533.0002339

49. Maia J, Ramos NMM, Veiga R (2019) A new durability assessment methodology of thermal mortars applied in multilayer rendering systems. Construction and Building Materials 222:654663. doi:10.1016/j.conbuildmat.2019.06.178 